\title{
EVALUATION OF TENSILE PROPERTIES OF 3D PRINTED PETG SPECIMEN AS PER ASTM STANDARDS
}

\section{S. SWETHA, PRIYADARSINI MORAMPUDI, K. ARUNA PRABHA \& PUTHA PRASAD KUMAR}

VNRVJIET, Hyderabad, Telangana, India

In the manufacturing of parts, additive manufacturing using $3 d$ printing is playing a very important role by providing an alternative to the existing conventional manufacturing processes. The strength of $3 D$ printed parts is still in its infant stages and an area of current research. Polyethylene terephalate glycol modified (PETG) is a modified version of PET which is most commonly used plastic in the world. It is a biodegradable and recyclable material and is also one of the most compatible materials in Fused Deposition Modelling (FDM) based 3D printing modelling. According to the ASTM standards testing on PETG material is done as per ASTM D638 type-I standard. In the project, ASTM D638 type-IV, D695 specimens have been printed on a GARUDA 3D FDM printer using the PETG material and are subjected to tensile test by changing the infill percentages and layer height parameters respectively. The process involves preparation of specimens according to ASTM standards in CATIA V5 software followed by slicing using the SIMPLIFY 3D software. 3-D printing of PETG material is done on a GARUDA 3D printer. The experimental results are then to be validated using the ANSYS simulation software and the difference in the experimental and simulated values are calculated.

KEYWORDS: PETG, FDM, GARUDA 3D Printer, SIMPLIFY 3D Software \& ASTM D638
\end{abstract}

Received: Jun 08, 2020; Accepted: Jun 28, 2020; Published: Sep 15, 2020; Paper Id.: IJMPERDJUN20201254

\section{INTRODUCTION}

Rapid prototyping is a technology which is used to produce parts with the help of Computer Aided Design (CAD) software data. Traditional manufacturing method is a subtractive method whereas, this method is an advanced method which is capable of reducing the manufacturing time, simplified process and reducing the material waste[1].

Polyethylene terephthalate (PET) is most commonly used plastic in the world. PETG is the modified version of PET here 'G stands for glycol modified'. It is used for manufacturing thousands of consumer products like delivering and packaging of food beverages[2]. These components are made using traditional manufacturing processes like blow molding. They can also be made using additive manufacturing process like 3D- Printing which uses PETG as raw material and it is deposited layer by layer from the extruder. It is very important that the strength of the 3D Printed parts are known for proper functioning and applications. To test the strength of 3D printed PETG parts, ASTM standards are available; for tensile testing ASTM D638 standard is used[3].

For ASTM D638 there are four sub-types; however it has been noticed ASTM D638 type-I is widely used. In this work, it is proposed to perform tests to evaluate tensile strength of PETG specimens as per ASTM D638 typeIV.

Aim of the work is to design, validate and 3D print the specimens by changing the parameters like infill percentage and layer thickness. ASTM tensile test specimens were printed using PETG material. The specimens are then subjected to tensile load on Universal Testing Machine (UTM). Modeling of the component is done in CATIA 
V5 software. If there are any errors in the STL file during modeling or may have occured during conversion it has to be rectified using Netfabb software. The experimentally tested specimen values are to be validated using the ANSYS software. The difference in the experimental and ANSYS values will be calculated.

\section{METHODOLOGY}

\section{Problem Identification}

3D printed parts Strength is crucial for proper functioning of the part for its application. To test the 3D printed parts strength ASTM standards are available.

\section{Design Of Specimens}

Tensile test specimens have to be modeled as per ASTM D638

\section{Change of Parameters}

Change in the parameters of printing like infill percentage and the change in the layer thickness of the each layer to be printed. The infill percentages we are using are $50 \%$ and $100 \%$. The layer heights chosen are $0.1 \mathrm{~mm}$ and $0.3 \mathrm{~mm}$.

\section{D Printing}

Validated model of the specimen have to be converted to STL file and then 3D print using GARUDA 3D.

\section{Experimental Testing}

3D printed specimens are to be then tested using Universal Testing Machine (UTM) to obtain stress, strain and modulus values.

The thickness of specimen for tensile test is $4 \mathrm{~mm}$ and gauge length is $33 \mathrm{~mm}$. Overall length of the specimen is $115 \mathrm{~mm}$. The raw material used in present project is PET-G supplied by GARUDA 3D.

Table 1: ASTM D638 Type - IV Tensile Specimen Dimensions.

\begin{tabular}{|l|c|}
\hline \multicolumn{1}{|c|}{ Dimensions } & Type IV $(\mathbf{m m})$ \\
\hline L- Length of narrow section & 33 \\
\hline W- Width of narrow section & 4 \\
\hline LO- Length overall & 115 \\
\hline WO- Width overall & 19 \\
\hline R- Fillet radius & 14 \\
\hline RO- Outer radius & 25 \\
\hline D- Distance between grips & 65 \\
\hline G- Gage length & 25 \\
\hline
\end{tabular}

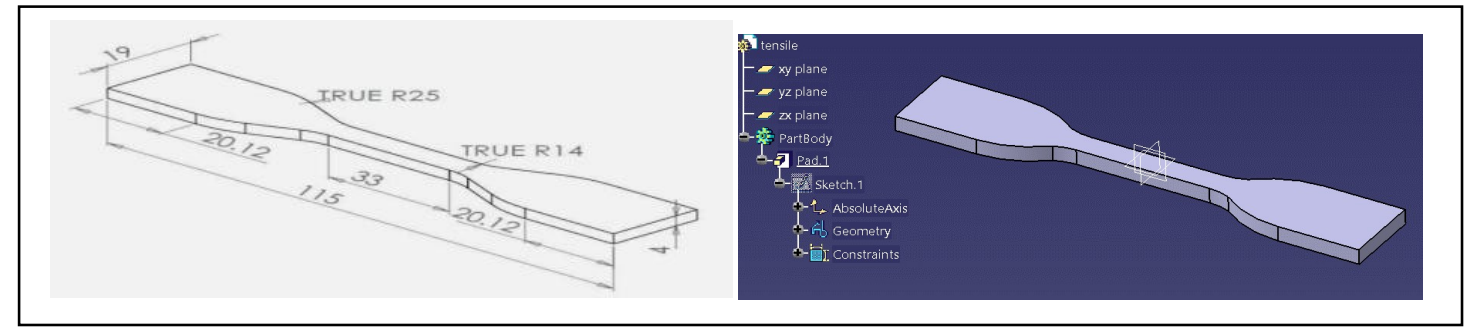

Figure 1: Detailed Dimensions and CAD Model of Tensile Specimen. 


\section{3D PRINTING OF THE ASTM SPECIMENS}

\subsection{Parameter Setting}

Table 2: Parameters Value(100\% Infill and $0.1 \mathrm{~mm})$

Table 3:Parameters Value (50\% Infill and $\mathbf{0 . 1 \mathrm { mm } )}$

\begin{tabular}{|c|l|c|}
\hline Sl. No. & Name of the Parameter & Set Value \\
\hline 1 & Nozzle count & 1 \\
\hline 2 & Travelspeed $(\mathrm{m} / \mathrm{sec})$ & 0.06 \\
\hline 3 & Infill $(\%)$ & 100 \\
\hline 4 & Layer height $(\mathrm{m})$ & 0.0001 \\
\hline 5 & Number of shells & 2 \\
\hline Sl. No. & Name of the parameter & Set value \\
\hline 1 & Nozzle count & 1 \\
\hline 2 & Travelspeed $(\mathrm{m} / \mathrm{sec})$ & 0.055 \\
\hline 3 & Infill $(\%)$ & 50 \\
\hline 4 & Layer height $(\mathrm{m})$ & 0.0001 \\
\hline 5 & Number of shells & 2 \\
\hline
\end{tabular}

Table 4: Parameters Value(100\% Infill and 0.3mm)

\begin{tabular}{|c|l|c|}
\hline Sl. No. & Name of the Parameter & Set Value \\
\hline 1 & Nozzle count & 1 \\
\hline 2 & Travel speed $(\mathrm{m} / \mathrm{sec})$ & 0.12 \\
\hline 3 & Infill $(\%)$ & 100 \\
\hline 4 & Layer height $(\mathrm{m})$ & 0.0003 \\
\hline 5 & Number of shells & 2 \\
\hline
\end{tabular}

Table 5:Parameters Value (50\% Infill and $0.3 \mathrm{~mm})$

\begin{tabular}{|l|l|c|}
\hline Sl. No. & Name of the Parameter & Set Value \\
\hline 1 & Nozzle count & 1 \\
\hline 2 & Travel speed $(\mathrm{m} / \mathrm{sec})$ & 0.45 \\
\hline 3 & Infill $(\%)$ & 50 \\
\hline 4 & Layer height $(\mathrm{m})$ & 0.0001 \\
\hline 5 & Number of shells & 2 \\
\hline
\end{tabular}

\section{FINITE ELEMENT ANALYSIS OF THE SPECIMENS}

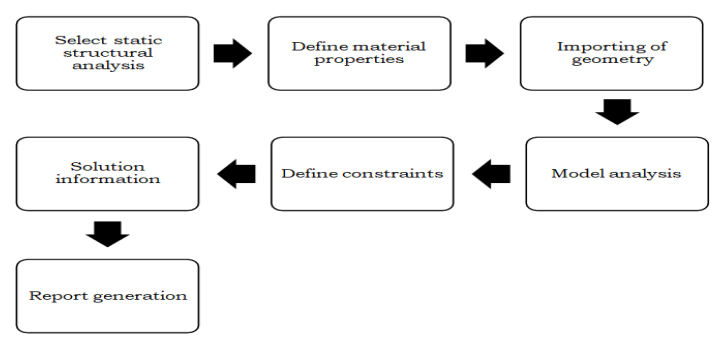

Figure 2: Steps Involved in Static Structural Analysis.

\section{Analysis Procedure}

The analysis is carried out using the ANSYS 16.2 workbench. Simulation module used is static structural analysis, with one end fixed. Figure 1 shows an overview of analytical procedure followed in ANSYS software. ANSYS analysis is performed to check for random errors. Fig 2 shows the general procedure followed in FEA. 
The analysis is carried out on the tensile specimens. The material properties of the specimen are to be loaded in software. The specimen is analyzed for stress, deformation and strain for the loads that are obtained during experimental analysis.

\section{RESULTS}

\subsection{Stress Analysis of Tensile Specimen for Different Loads}

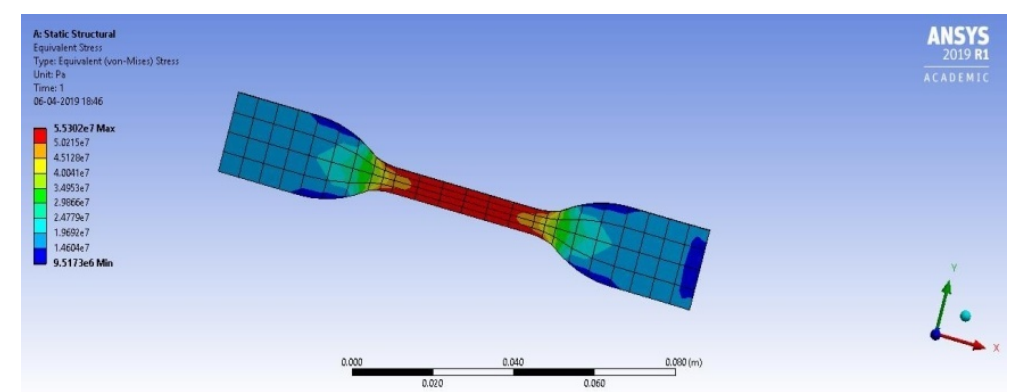

Figure 3: For Tensile Load of 1214.06 N.

The Stress analysis is carried out on the tensile test specimen for different loads acting on the specimen. Stress is induced in the specimen after the application of tensile load. According to theory of failure the stress is highest at the point where cross section of area changes and is prone to fail at that point. Here, Gauge length has the highest amount of stress values when compared to the other regions of specimen when load is applied beyond its elastic limit. Behavior of the specimens at the different applied tensile loads are shown from figure 3 - 6

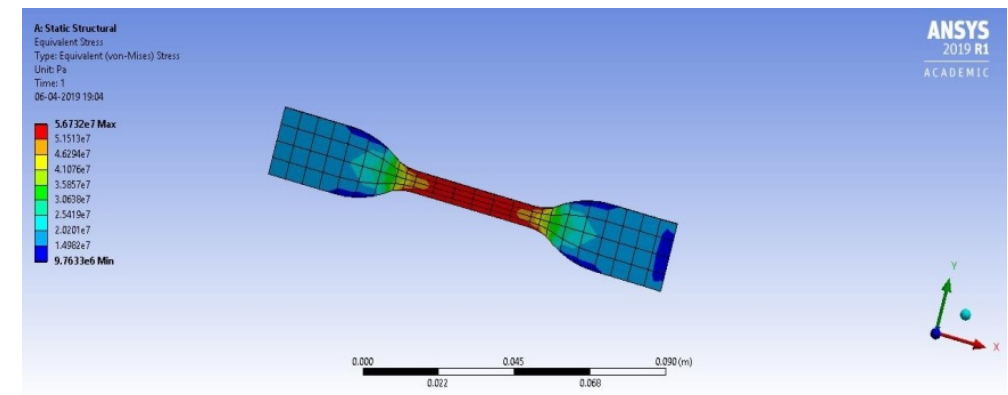

Figure 4: For Tensile Load of 1245.44 N.

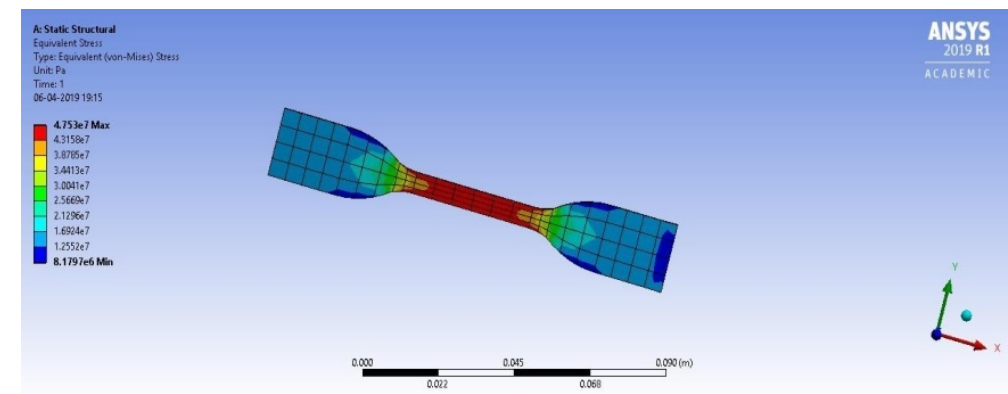

Figure 5: For Tensile Load of 1043.43 N. 


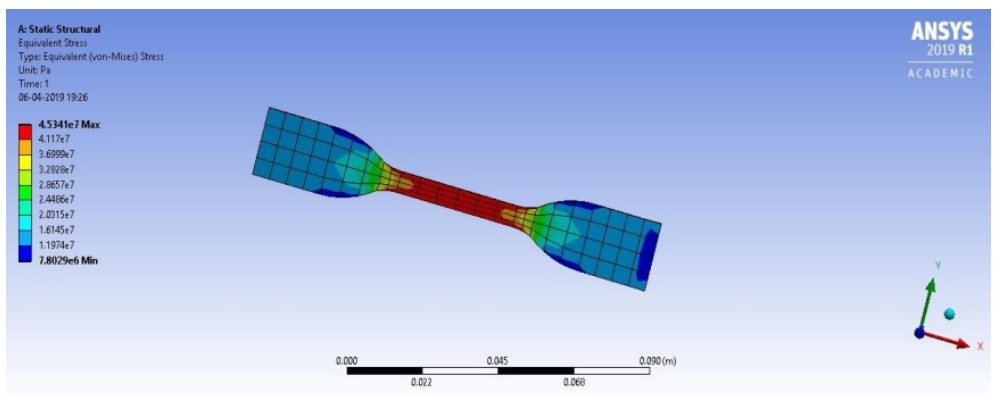

Figure 6: For Tensile Load of 995.37.44 N.

Stress at $1245.44 \mathrm{~N}$ is maximum than all the loads applied. This is because the applied load is more in the affecting area which leads to high concentration of stresses at gauge length area.

Table 6: Stress Values for Different Tensile Loads

\begin{tabular}{|c|c|c|c|}
\hline Layer Thickness & Specimen & Load $(\mathbf{N})$ & Stress $\left(\mathbf{N} / \mathbf{~ m m}^{\mathbf{2}}\right)$ \\
\hline \multirow{2}{*}{0.1} & 1 & 1214.06 & 55.30 \\
& 2 & 1245.44 & 56.73 \\
\hline \multirow{2}{*}{0.3} & 1 & 1043.33 & 47.53 \\
& 2 & 995.37 & 45.34 \\
\hline
\end{tabular}

\subsection{Deformation Analysis of Tensile Specimen at Different Loads}

Deformation analysis is done for tensile test specimen with different loads acting on the specimen. Deformation is induced on specimen after the application of tensile load. Due to the application of load and work done by external forces acting on the specimen large deformation is observed as shown in the figure 7 - 10 .

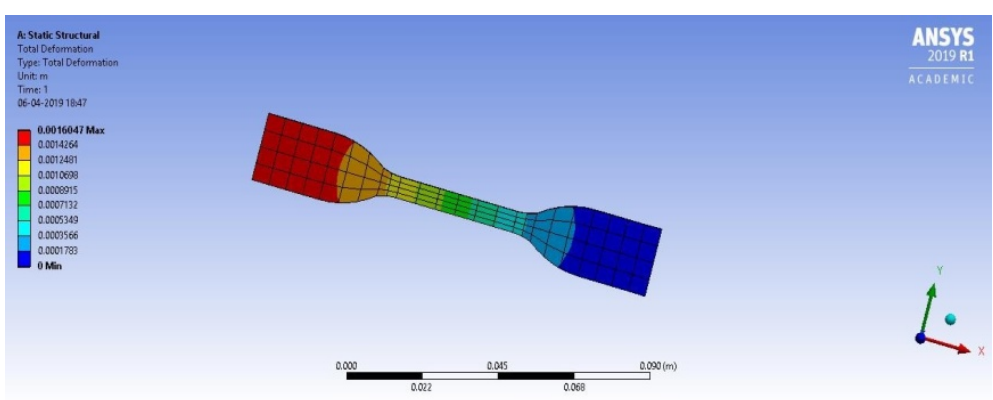

Figure 8: Deformation for Load of $1214.06 \mathrm{~N}$.

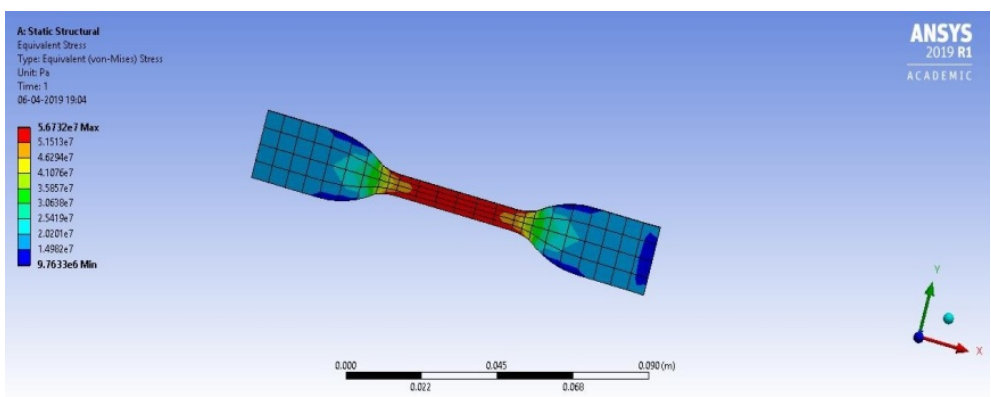

Figure 8: Deformation for Load of 1245.44 N. 


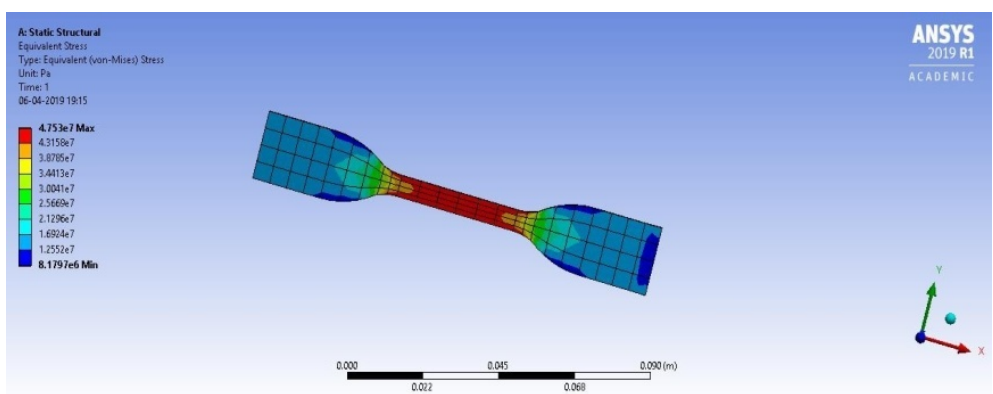

Figure 9: Deformation for a Load of 1043.43N.

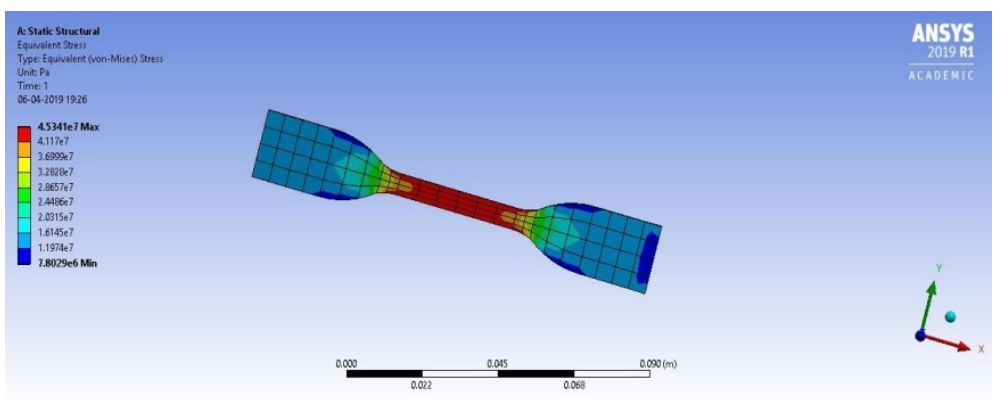

Figure 10: Deformation for a Load of 995.37.44 N.

Amongst all the loads applied and deformations recorded the deformation is maximum at the $1245.44 \mathrm{~N}$ load. The reason behind the maximum deflection is the concentration of load applied on the specimen is maximum and is prone to deflection

Table 7: Deformation Values for Different Tensile Loads

\begin{tabular}{|c|c|c|c|}
\hline Layer Thickness & Specimen & Load (N) & Deformation \\
\hline \multirow{2}{*}{0.1} & 1 & 1214.06 & 1.61 \\
& 2 & 1245.44 & 1.64 \\
\hline \multirow{2}{*}{0.3} & 1 & 1043.33 & 1.37 \\
& 2 & 995.37 & 1.31 \\
\hline
\end{tabular}

\subsection{Strain Analysis of Tensile Specimen for Different Loads}

Strain analysis is done for the tensile test specimen with different loads acting on specimen. Strain is induced in the specimen after the application of tensile load. Strain is high at the gauge length section when compared to other sections of the specimen because of the reason that there is increase in length of the specimen and decrease in the cross section area of the specimen. Strains at different loads are shown in figure $11-14$.

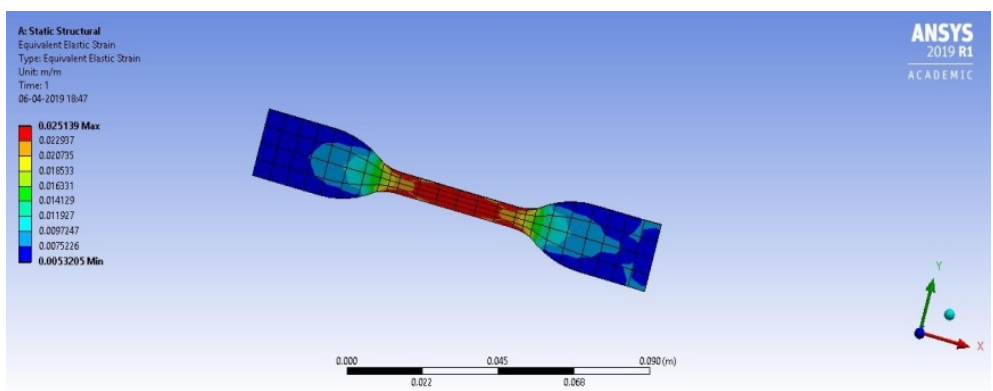

Figure 11: Strain for a Load of 1214.06 N. 


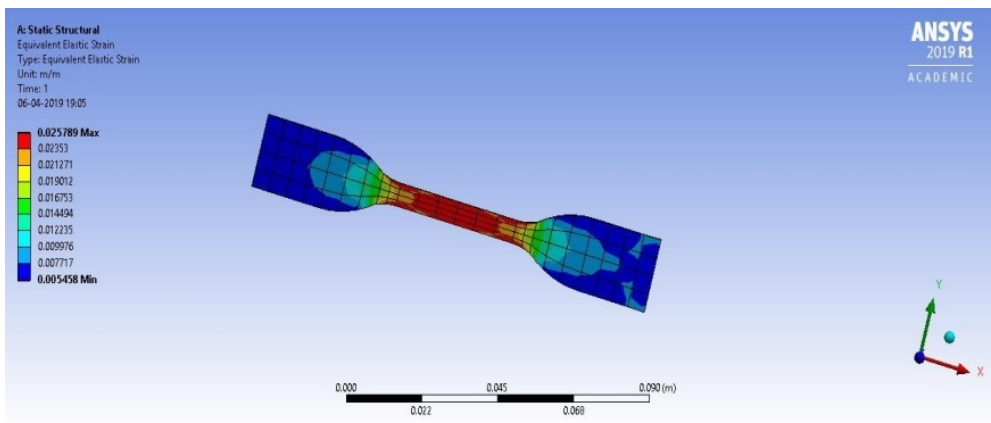

Figure 12: Strain for a Load of 1245.44 N.

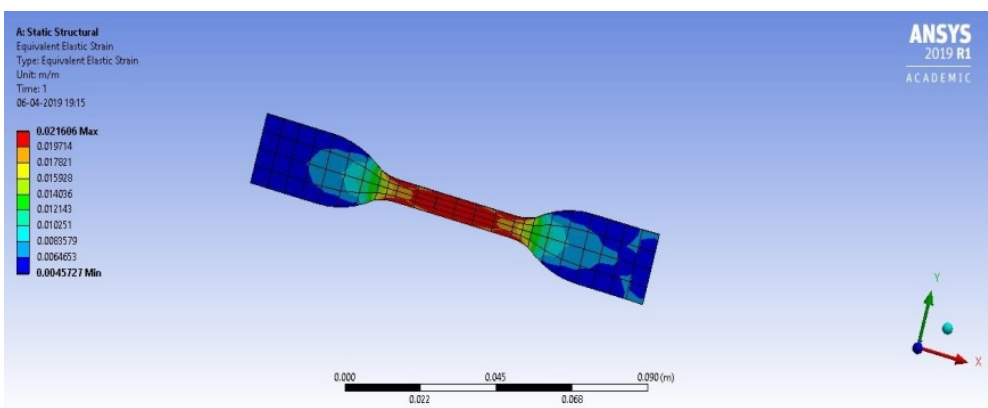

Figure 13: Strain for a Load of 1043.43 N.

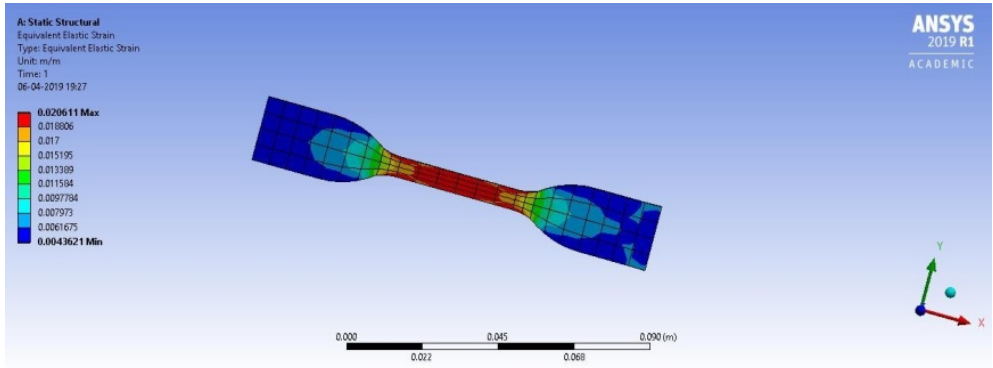

Figure 14: Strain for a Load of 995.37.44 N.

For a load of $1245.44 \mathrm{~N}$ the stress is maximum than at all the other loads applied. This is because of the fact that applied load is affecting the area which is less and length is more. This leads to high concentration of strain at a point. The maximum strain is 0.025 .

Table 8: Strain Values for Different Tensile Loads

\begin{tabular}{|c|c|c|c|}
\hline Layer Thickness & Specimen & Load (N) & Strain (\%) \\
\hline \multirow{2}{*}{0.1} & 1 & 1214.06 & 2.51 \\
& 2 & 1245.44 & 2.58 \\
\hline \multirow{2}{*}{0.3} & 1 & 1043.33 & 2.16 \\
& 2 & 995.37 & 2.06 \\
\hline
\end{tabular}

\section{EXPERIMENT RESULTS}

Following are the results observed for tensile tests for different varied 3D printing parameters. 
Table 9: For 100\% Infill and 0.1mm Layer Thickness

\begin{tabular}{|c|c|c|c|}
\hline Parameters (100\% Infill 0.1mm) & Max. Force & Max. Stress & Max. Strain \\
\hline Units & $\boldsymbol{N}$ & $\mathbf{2 ~ N / m m}$ & \% \\
\hline 1 & 1245.44 & 51.21 & 13.14 \\
\hline 2 & 1214.1 & 49.92 & 12.37 \\
\hline Mean & 1229.77 & 50.57 & 12.76 \\
\hline
\end{tabular}

Table 10: For $100 \%$ Infill and $0.3 \mathrm{~mm}$ Layer Thickness

\begin{tabular}{|c|c|c|c|}
\hline Parameters (100\% infill 0.1mm) & Max. force & Max. stress & Max. strain \\
\hline Units & $\boldsymbol{N}$ & $\mathbf{2 ~ N / \mathbf { m m }}$ & $\mathbf{\%}$ \\
\hline 1 & 1043.33 & 47.53 & 12.64 \\
\hline 2 & 995.37 & 40.73 & 15.09 \\
\hline Mean & 1019.35 & 44.13 & 13.87 \\
\hline
\end{tabular}

Table 11: For 50\% Infill and 0.1mm Layer Thickness

\begin{tabular}{|c|c|c|c|}
\hline Parameters (50\% infill 0.1mm) & Max. force & Max. stress & Max. strain \\
\hline Units & $\boldsymbol{N}$ & $\mathbf{2 ~ N / \mathbf { m m }}$ & $\mathbf{\%}$ \\
\hline 1 & 857.1 & 35.24 & 14.06 \\
\hline 2 & 937.5 & 38.55 & 11.31 \\
\hline Mean & 897.3 & 36.90 & 12.69 \\
\hline
\end{tabular}

Table 12 For $50 \%$ Infill and $0.3 \mathrm{~mm}$ Layer Thickness

\begin{tabular}{|c|c|c|c|}
\hline Parameters (50\% Infill 0.1mm) & Max. Force & Max. Stress & Max. Strain \\
\hline Units & $\boldsymbol{N}$ & $\mathbf{2 ~ N / \mathbf { m m }}$ & \% \\
\hline 1 & 640.37 & 26.33 & 8.09 \\
\hline 2 & 589.38 & 24.23 & 8.91 \\
\hline Mean & 615.38 & 25.28 & 8.50 \\
\hline
\end{tabular}

\section{CONCLUSIONS}

- There has been a clear decrease in the tensile strength of the components when there is a decrease in the \%infill and the increase in layer thickness. The change has been gradual but not exponential.

As strength of the 3D printed PETG specimens are nearly equal to that of the conventionally produced specimens, we can use 3D printed PETG in place of conventional ones in food packaging industries, medical implants etc...

The tensile and compressive strength tests have been experimentally performed and the validation has been done using static structural analysis in ANSYS software. There will be a $10 \%$ error in the simulated values which are reflected in the final results. The final difference between the experimental and simulated values is up to $5 \%$ (which is acceptable).

\section{REFERENCES}

1. Yan Y, Li S, Zhang R, Lin F, Wu R, Lu Q, Xiong Z, Wang X. Rapid prototyping and manufacturing technology: principle, representative technics, applications, and development trends. Tsinghua Science and Technology. 2009 Jun;14(S1):1-2.

2. Popescu D, Zapciu A, Amza C, Baciu F, Marinescu R. FDM process parameters influence over the mechanical properties of polymer specimens: A review. Polymer Testing. 2018 Aug 1;69:157-66.

3. Hossain MS, Ramos J, Espalin D, Perez M, Wicker R. Improving tensile mechanical properties of FDM-manufactured specimens via modifying build parameters. InInternational Solid Freeform Fabrication Symposium: An Additive Manufacturing Conference. Austin, TX 2013 Aug 12 (Vol. 2013, pp. 380-392)..

4. Mutyala RS. Effect of FDM process parameters on the mechanical properties of CFR-PEEK. 